\title{
Comentario
}

\section{Relaciones de género y subjetividad: debates actuales}

\author{
Irene Meler
}

\begin{abstract}
El trabajo de Roxana Hidalgo Xirinachs toma como objeto el análisis de las representaciones sociales acerca de las mujeres, y en particular, aquellas que sancionan negativamente la expresión de la hostilidad femenina. La autora plantea que los desarrollos psicoanalíticos también suponen en muchos casos, la existencia de imágenes mistificadas acerca de la feminidad.

Considero que se trata de un estudio amplio y muy bien documentado, al que solo puedo agregar algunos comentarios que me ha sugerido su lectura. Estas reflexiones son la expresión de un proceso muy frecuente, donde el contacto con el pensamiento de colegas que trabajan en el mismo campo, estimula la discusión y permite complementar las observaciones expuestas por el autor.
\end{abstract}

Concuerdo con la importancia que Roxana Hidalgo asigna a las representaciones colectivas sobre la feminidad a lo que agrego que éstas interactúan de modo forzoso con las representaciones acerca de la masculinidad. Estos estereotipos condensan las prescripciones y las proscripciones vigentes acerca de las relaciones sociales entre los géneros sexuales. Tienen un rol relevante en la construcción de la subjetividad, a la que plasman a través de arreglos instituidos y prácticas de vida que forman parte de lo que se ha denominado como "sentido común".

Los seres humanos construyen su subjetividad de acuerdo con el sistema sexo género (Rubin, 1975), y también en desacuerdo con el mismo, frente al que se involucran de modo regular en diversas clases de transgresiones. La identidad de género, si es que elegimos mantener con fines prácticos esta expresión algo reificante, se asemeja a un mosaico (Meler, 1987), compuesto sobre la base de identificaciones disarmónicas que van configurando las instancias del aparato psíquico, las defensas predominantes y las particularidades del deseo erótico y de la elección de objeto.

Ningún ser humano encarna al estereotipo, por el contrario, se aleja del mismo de modos específicos que a veces hacen a la formación del carácter, en otros casos se relacionan con los ideales propuestos para el Yo o con las habilidades que integran el Yo de funciones y en ocasiones determinan modos particulares de estructurar el deseo erótico u hostil. Sujeto y estereotipo no coinciden, pero los estereotipos contribuyen a la construcción subjetiva.

Es por ese motivo que el estudio de las representaciones colectivas hegemónicas y el seguimiento del proceso de transformación que experimentan en la actualidad interesa a quienes trabajamos en el campo de la subjetividad.

Como bien señala la autora, las representaciones que atraviesan los discursos literarios, científicos y políticos, se fraguan en una matriz alimentada por las relaciones de poder. En la Modernidad, mientras el héroe cultural masculino encarnó la racionalidad humana y el esfuerzo transformador de la Naturaleza, se reservó para las mujeres la expresión de una metáfora acerca del mundo natural domeñado. Me permito disentir en lo que se refiere a considerar que la discriminación se maximizó en ese período. Las representaciones del Mundo Antiguo o del Medioevo no fueron menos sexistas que las modernas. Considerar a las mujeres como guerreros castigados por su cobardía que debieron reencarnar bajo esa forma denigrante, tal como ocurrió en la Antigüedad, o como siervas del demonio, -representación hegemónica que avaló el sexocidio cometido en el Medioevo a través de la quema de las acusadas de brujería-, no parece más halagador que la imagen, al menos seductora, de la "hembra natural". Esta erotización de la subordinación social que se produjo durante la Modernidad, nos remite al pensamiento de Godelier (1986), cuando el autor se refiere a la sexualidad como una "máquina ventrílocua" a la que se hace expresar relatos que afirman la dominación social masculina. Esta dominación no es solo simbólica sino material y las transformaciones contemporáneas, que disuelven hasta cierto punto las fronteras antes rígidas entre los géneros, evidencian también cambios económicos relacionados con el mercado de trabajo y procesos políticos, vinculados con la participación ciudadana de las mujeres. Es por eso que integro en mi marco teórico una amalgama específica entre la importancia que el 
psicoanálisis asigna a la psicosexualidad en la construcción del psiquismo y el reconocimiento de la operatividad de las relaciones de poder para construir subjetividades (Meler, 2000) .

En la Postmodernidad algunos sectores de mujeres se han modernizado y avanzaron de forma significativa hacia la plena condición ciudadana. En la década del ' 60 se produjo un ingreso masivo de mujeres a la educación superior y esta masa crítica percibió prontamente el sesgo androcéntrico, cuando no sexista, de las teorías fundantes de las disciplinas sociales y humanas. Esta perspectiva sesgada era esperable en corpus teóricos producidos mayormente por varones, en el contexto de sociedades dominadas por los hombres. El desarrollo de los estudios de mujeres y posteriormente de los estudios de género, da cuenta de la visibilidad que adquirió la diferencia sexual como origen de una modalidad particular de estratificación social y al mismo tiempo, como fuente de tendencias diferenciales para la construcción del psiquismo. La participación social de las mujeres se ha mantenido atrapada al interior de una paradoja que no debe ser resuelta: la tensión entre la mimesis con el modelo del sujeto autónomo masculino y la reivindicación de la legitimidad del reconocimiento de las diferencias, o sea de la especificidad de la experiencia femenina.

El análisis de Roxana Hidalgo acerca de las diversas corrientes teóricas dentro del psicoanálisis se enmarca en la consideración de las teorías científicas como productos históricos que buscan y al mismo tiempo crean sentido. Este sentido será siempre el de un sector social, o sea un sentido situado.

El trabajo presenta una síntesis muy lograda de diversas tendencias psicoanalíticas influidas por los aportes de los estudios interdisciplinarios de género. Respecto de la valorización que realiza acerca de los aportes de Judith Kestenberg, me parece oportuno realizar una aclaración. Si bien resulta meritorio todo intento por conceptuar la psicosexualidad femenina sobre la base de la especificidad de la experiencia de las mujeres en lugar de abordarla como negativo o simétrico inverso de la psicosexualidad masculina erigida en patrón o modelo, debemos recordar que no existe acceso al cuerpo si no es a través de la imagen de los otros significativos, el vínculo con ellos y su discurso. Las discusiones que se plantearon tempranamente entre psicoanalistas acerca de la existencia de una percepción de la vagina en las niñas, carecen hoy día de relevancia, porque no planteamos una relación connatural entre cuerpo erógeno y aparato psíquico. los nexos entre cuerpo y representación son más complejos. En ese sentido, la postura kleiniana (Klein, 1933) acerca de la existencia de una feminidad primaria basada en el conocimiento inconsciente de la vagina resulta hoy día, según opino, tan insostenible como innecesaria. Las niñas son femeninas en la mayor parte de los casos, pero esto no ocurre porque su psiquismo se estructure sobre la percepción inconsciente de sus genitales internos, tal como sostenía Klein. Como bien lo demostraron los estudios de John Money (1982) y de Robert Stoller (1968), la asignación de género que realizan sus padres cuando ellas nacen, determina proyectos identificatorios específicos y diversos de aquellos elaborados para los niños. Ese es el factor principal al que podemos considerar responsable de la feminidad o de la masculinidad subjetiva. La respuesta humana bipolar ante niñas y varones, los acompaña, como expresa Money, "desde la cuna hasta la tumba". Por lo tanto, el deseo de tener hijos no debe sustentarse en las sensaciones cenestésicas vaginales, sino en la identificación de la niña con la madre y en la operatividad de los discursos colectivos que asigna a las mujeres el ejercicio de la maternidad.

En cuanto al comentario de la autora sobre Nancy Chodorow, una de las psicoanalistas norteamericanas que se inscriben en "la escuela del medio", o sea en la tradición winnicottiana, considero que la crítica que se ha realizado acerca de que su relato replica la polaridad existente entre los géneros es injustificada. Chodorow buscó dar cuenta de las tendencias subjetivas diferenciales entre los géneros refiriéndolas a la institución de la crianza materna y a las diferencias que esta instala entre mujeres y varones en lo que se refiere al vínculo temprano establecido entre la madre y el bebé. Sus observaciones han sido muy agudas y ordenadoras. No pretendieron tener una vigencia trans histórica, y de hecho, se observan modificaciones de estos estilos subjetivos en aquellos casos donde la crianza es compartida por ambos padres desde el inicio. Acerca de este punto, he realizado un ensayo prospectivo sobre la construcción de la subjetividad en las familias postmodernas (Meler, 1998). El análisis realizado por Chodorow fue producto de sus observaciones realizadas durante la década del '70. Se refirió a la subjetivación genérica tal como se desarrolla en las familias caracterizadas por una estricta división sexual del trabajo y el consiguiente dominio masculino. El hecho de que hoy resulten algo obsoletas cuando intentamos aplicarlas a ciertos sectores sociales modernizados, nos debe alertar acerca de la velocidad del cambio social y del desafío que esta circunstancia supone para quienes estudiamos la subjetividad. En una entrevista que realizamos junto con Mabel Burin a Nancy Chodorow en París, en la reunión de los Estados 
Generales del Psicoanálisis, la autora expresó que en la actualidad no sostiene con el mismo énfasis que antes su propuesta de crianza compartida por ambos padres. Reconoce una especificidad a la relación entre la madre y el hijo que considera debe ser respetada. En algunos casos, su argumentación fue utilizada para negar el apoyo conyugal o gubernamental a las madres de hijos pequeños. De modo que el paso del tiempo sirve para matizar algunos hallazgos, sin que por ese motivo pierdan validez.

Personalmente considero que cuando la crianza compartida es posible y se cumple efectivamente, todos nuestros conceptos acerca del desarrollo infantil se ven necesitados de una profunda reformulación.

La descripción freudiana del período preedípico, donde el padre es solo para la niña "un molesto rival", no se aplica a la experiencia intersubjetiva en el vínculo con un padre que alimenta, higieniza y hace dormir a la criatura. El amor temprano hacia el progenitor masculino sienta las bases para un deseo heterosexual genuino, y no, como describió Chodorow, una aceptación formal de la alianza conyugal por parte de muchas mujeres adultas.

El "cambio de objeto" planteado por Freud con respecto de las niñas, no tendría las mismas características, ya que se pasaría del apego preedípico hacia el padre al amor edípico erotizado, de forma semejante a lo que ocurre con el niño respecto de la madre.

La cercanía del varón con el padre permitiría una construcción de la identidad masculina sobre bases más sólidas, lo que contribuiría a la disminución de su habitual carácter reactivo. La integración del amor erótico del varoncito hacia su padre, podría facilitar la superación de la homofobia masculina.

Volviendo al trabajo de Roxana Hidalgo, vemos que el último acápite presenta un análisis sensible acerca de los avatares contemporáneos de la construcción de la subjetividad de las mujeres. En especial, se focaliza en el tratamiento simbólico que han recibido las imágenes de la agresividad femenina, cuya implementación constructiva es necesaria para el logro de un proceso de diferenciación que rescate a las niñas de la fusión con el modelo materno. La autora analiza las imágenes que propician la sanción negativa del deseo hostil de las mujeres y lo condenan a uno de sus destinos clásicos: vuelta contra sí misma, lo que conduce a la depresión, o transformación en lo contrario, que estimula la exageración de una ternura de carácter reactivo. La contrapartida de la mujer masoquista y depresiva es "la malvada", imagen arcaica aterradora de la madre todopoderosa de los primeros estadios de la vida humana. Numerosos autores se han referido a este aspecto terrorífico de la imago materna, entre ellos Jeannine Chasseguet Smirgel (1977, p. 142-144):

“...el niño, sea del sexo que sea, tiene de la mejor y de la más tierna de las madres una imagen terrorífica en el inconsciente, resultante de la hostilidad proyectada sobre ella por el hecho de su propia impotencia". "La imago tutelar de la buena madre todopoderosa y la imago terrorífica de la mala madre omnipotente están en oposición a la representación de la madre castrada. Ese pecho generoso, esos flancos fecundos, esa dulzura, ese calor, esa plenitud, esa abundancia esas mieses, la Tierra, la Madre... Esa frustración, esa invasión, esa intrusión, ese mal, esa enfermedad, la Muerte, la Madre."

En la Argentina, Mabel Burin (1987) ha realizado una interesante discriminación acerca de los destinos posibles de la hostilidad. Por un lado, podría dar lugar a una descarga afectiva. Por el otro en determinadas condiciones puede generar el surgimiento de un deseo hostil diferenciador, que estimule la ruptura de identificaciones anteriores para dar lugar al establecimiento de nuevos enlaces. De ese modo nuevos deseos pueden advenir, ser construidos. La autora se refiere en particular a la posibilidad de hallar reemplazo al deseo de ser madres, cuando el crecimiento de los hijos coloca a las mujeres tradicionales ante la amenaza de vacancia de rol social y por lo tanto, las hace vulnerables a la depresión. La creación de nuevos deseos y proyectos vitales permite mejores perspectivas en cuanto a la salud mental femenina. Este tipo de modelo teórico permite superar la demonización de la hostilidad femenina y otorgarle legitimidad.

La autonomía ha sido un ideal muy caro a las mujeres durante los fines de la Modernidad. Se ha debatido acerca de su cariz individualista y algunos autores y autoras prefirieron recurrir a concepciones que enfatizaran el relacionamiento o la interdependencia. Ronald Fairbain (1962) ha sido un pionero que dentro de la escuela inglesa de psicoanálisis planteó un modelo evolutivo que parte de una situación de dependencia infantil para arribar en el mejor de los casos a la dependencia madura. Las fantasías de independencia son producto de una sociedad individualista y si bien las mujeres hemos debido apropiarnos de ellas para sustraernos a la condición de objeto, es hora de 
reconocer la interrelación existente entre los sujetos sin temor a la dilución de nuestro ser en ese empeño.

Es por eso que el enfoque psicoanalítico intersubjetivo, desarrollado por Jessica Benjamin (1996 y 1997) y al que suscribe entre muchos otros Emilce Dio Bleichmar (1997) en su última obra, abre las puertas para la superación de la monótona relación entre el Sujeto Masculino Hegemónico y su Objeto de Deseo.

La propuesta consiste en superar la tradición intelectual que focalizaba el estudio de la subjetividad en la observación de procesos intra subjetivos, o sea en un individuo artificialmente aislado. Nacemos en un contexto relacional sin el cual no podemos subsistir ni humanizarnos. Es tiempo entonces de generar un enfoque teórico que de cuenta de este "ser en relación" característico de nuestra especie. El otro, el semejante, el objeto, se halla siempre presente, y no solo como imago, o sea como construcción subjetiva acerca del mismo, sino como alguien con existencia real, cuyas conductas nos afectan, ya sea para ampararnos o traumatizarnos.

Se trata de inaugurar un diálogo entre sujetos y ese diálogo implica una transformación que abarca desde las subjetividades hasta el orden social, económico y político.

\section{Referencias}

Benjamin, J. (1996) Los lazos de amor. Buenos Aires: Paidós.

Benjamin, J. (1997). Sujetos iguales, objetos de amor. Buenos Aires: Paidós.

Burin, M.; Bleichmar, E.; Coria, C.; Moncarz, E.; Carreño, D.; Velázquez, S.; Meler, I.; Castro, I. (1987). Estudios sobre la subjetividad femenina. Mujeres y salud mental. Buenos Aires: GEL.

Chasseguet Smirgel, J. (1964). La culpabilidad femenina. En Chasseguet Smirgel, J. (compiladora) La sexualidad femenina (pp. 119-155). Barcelona: Editorial Laia.

Chodorow, N. (1984). El ejercicio de la maternidad. Barcelona: Gedisa.

Dio Bleichmar, E. (1997). La sexualidad femenina. De la niña a la mujer. Buenos Aires: Paidós.

Fairbairn, R. (1962). Estudio psicoanalitico de la personalidad. Buenos Aires: Hormé.

Godelier, M. (1986). La producción de "Grandes Hombres". Poder y dominación en los baruya de Nueva Guinea. Madrid: Akal.

Klein, M. (1933/1970). El psicoanálisis de niños. Buenos Aires: Hormé.

Meler, I. (1987). Identidad de género y criterios de salud mental. En Burin, M. Burin, M.; Bleichmar, E.; Coria, C.; Moncarz, E.; Carreño, D.; Velázquez, S.; Meler, I.; Castro, I. Estudios sobre la subjetividad femenina. Mujeres y salud mental (pp. 351-374). Buenos Aires: GEL.

Meler, I. (1998). Construcción de la subjetividad en la familia postmoderna. Un ensayo prospectivo. En Burin, M. y Meler, I. (compiladoras) Género y familia. Poder, amor y sexualidad en la construcción de la subjetividad (pp. 373-398). Buenos Aires: Paidós.

Meler, I. (2000). El ejercicio de la sexualidad en la Postmodernidad. Fantasmas, prácticas y valores. En Meler, I. y Tajer, D. (compiladoras) Psicoanálisis y género. Debates en el foro (pp. 179-210). Buenos Aires: Lugar Editorial.

Money, J. (1955/1982). Desarrollo de la sexualidad humana. Madrid: Morata.

Rubin, G. (1975). The traffic in women. Notes on the 'Political Economy' of sex. En Reiter, R. (compilador). Toward an anthropology of women (pp. 141-160). Nueva York y Londres: Monthly Review Press.

Stoller, R. (1968). Sex and gender. Nueva York: Jason Aronson. 